\title{
Future of construction industry: COVID-19 and its implications on construction projects and risk management $-\mathbf{A}$ review
}

Kushal Adhikari $^{\mathrm{a}^{*}}$, Lochana Poudyal $^{\mathrm{a}}$

${ }^{a}$ Department of Civil, Environmental, \& Construction Engineering, Texas Tech University, Lubbock, USA

*Corresponding author

Kushal Adhikari, Ph.D. Candidate

Department of Civil, Environmental, \& Construction Engineering

Texas Tech University, Lubbock, USA

911 Boston Ave, Lubbock TX, 79409

Email: kushal.adhikari@ttu.edu; adhikari.kushal1992@gmail.com

Phone: 806.283 .0788 


\section{Contents}

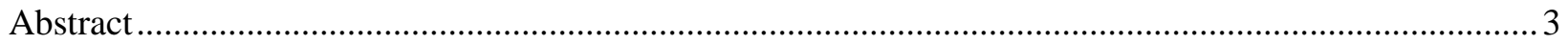

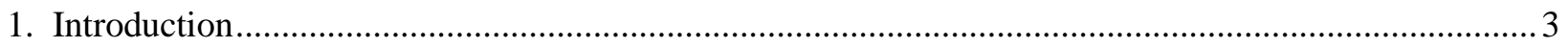

1.1 COVID-19 and construction - NORM, NEW NORM and Post COVID-19 NORM....................... 5

2. COVID-19 implications on construction industry ..................................................................... 7

2.1. Managing projects and construction risks during the coronavirus pandemic ….......................... 7

2.2 Keys to successful project planning and risk management during the coronavirus pandemic .......... 9

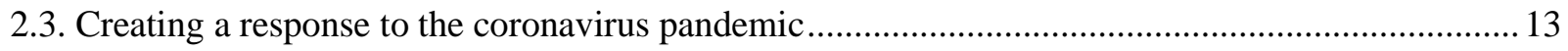

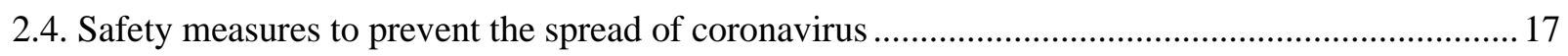

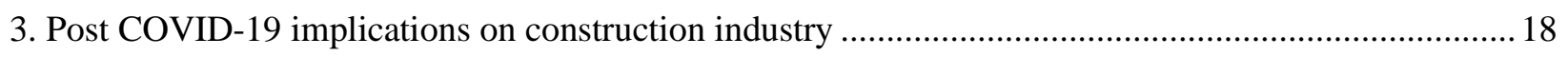

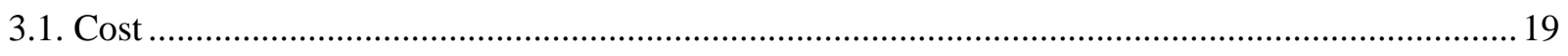

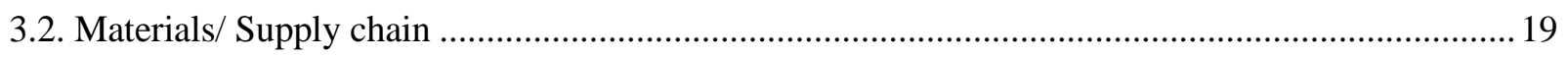

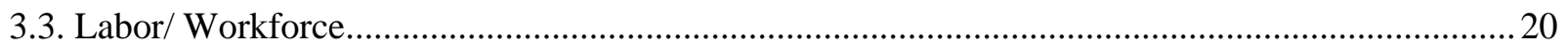

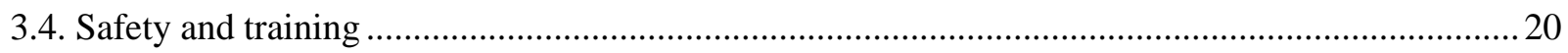

4. Future of construction: a transformation of work, workforce, and workplace ...................................2 21

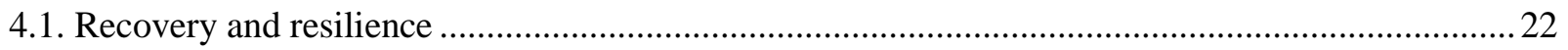

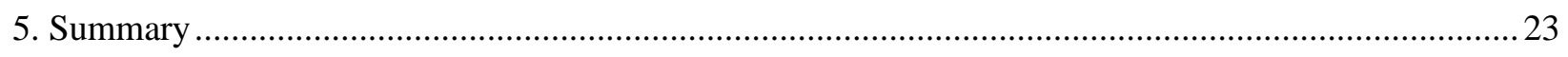




\begin{abstract}
The global coronavirus (COVID-19) pandemic has created a whole new set of risks in construction industries generating unprecedented delays, disruptions, and uncertainty on construction projects, and has forced the industries in adopting more sophisticated technologies while combating the reduced workforce on job sites. Further, the postpandemic era of construction is expected to be a lot different as the industries will embrace the technology as the augmentation and collaboration strategy. Thus, it will be extremely hard to sustain for construction industries in the absence of effective risk management. The existing risk plans need to be inspected for their capability of handling new risks arising from COVID-19 and the project managers will need to make the necessary revisions as needed. This paper discusses on past (NORM), present (NEW NORM), and future (Post COVID-19 NORM) of the construction industry and highlights key strategies for managing projects and construction risks during and post COVID-19 pandemic.
\end{abstract}

Keywords: COVID-19; pandemic; construction project; risk management; use of technology; recovery and resilience

\title{
1. Introduction
}

The Coronavirus Disease 2019 (COVID-19) pandemic has resulted in over 45 million confirmed cases and over million deaths globally (WHO, 2020). Global and dramatic spread of COVID-19 has traveled much faster than our response plan, and the risks such as this pandemic has been underestimated by project managers, governments, industries, and all others (Ozguler, 2020). The COVID-19 has already brought unprecedented economic and social impacts to many parts of the world and several sectors including, but not limited to, business, schools, universities, travel, tourism, hospitality, aviation, agriculture, petroleum and oil, manufacturing industry and construction industries (Gamil \& Alhagar, 2020; Laing, 2020; Nicola et al., 2020).

Construction and engineering projects around the world are being impacted by the COVID-19 pandemic in numerous ways, and many projects have stopped (Bailey et al., 2020). 
The safety measures such as travel restrictions, social distancing and quarantines have resulted in unprecedented delays, disruptions, increased construction cost, and uncertainty on construction projects with increasingly disrupting supply chains, contractor workforces and the availability of governmental personnel for project inspections (Robert et al., 2020) (Gallagher, 2020). And it is not yet clear how the construction industries will adopt once the recovery and rebuilding phase begins (Ozguler, 2020).

Construction is a risky business with numerous risks and uncertainty along the process (Adhikari et al., 2020). In addition to the typical risks, the impacts of COVID-19 pandemic and constantly changing and often inconsistent state, county and city orders has created a whole new set of risks and uncertainty in every construction projects resulting in limited activities or halt of the projects (gould+ratner, 2020). All the parties involved including owners, contractors and project managers are thus required to identify and manage all such risks while navigating this period of uncertainty, and risk analysis and management now will be a crucial practice than ever for construction industry and project managers. Additionally, it will be extremely hard to sustain for construction industries in the absence of effective risk management and will be a social challenge in building a sustainable future for mankind (Ozguler, 2020). The existing risk plans need to be inspected for its capability of handling of new risks arising from COVID-19 and the project managers will need to take necessary revisions as needed. The updated risk plan should ensure that the project is fully prepared for all eventualities and may require revision in key areas such as resources, communication, technology, and finance (Thornton, 2020).

With the rise of pandemic, experts in the fields have shared their opinions on impacts of COVID-19 on construction industry and construction projects. And many new articles pertaining to COVID-19 and the coping strategies are being published. This paper discusses on past 
(NORM), present (NEW NORM) and future (Post COVID-19 NORM) of the construction industry and highlights on key strategies for managing projects and construction risks during the COVID-19 pandemic and post COVID-19.

\subsection{COVID-19 and construction - NORM, NEW NORM and Post COVID-19 NORM}

"COVID -19 will likely be known as the trigger that changed the way the world sees and carries out business (Ozguler, 2020)". Prior to COVID-19, the company worked in group of teams where larger fraction worked in physical locations with very few members working remotely, and big offices, buildings and other fixed assets were considered mandatory for industries/organizations to operate. The current pandemic, however, brought significant changes in the construction industries and the fixed assets considered a must before no longer seems to be a necessity.

Under this NEW NORM, most industries have gone $100 \%$ virtual. The teams are meeting virtually and most of the works are performed virtually without need of workers to be physically present. However, this transition has not been easier for all the construction industries. Few industries that were open to virtual working prior to COVID-19 made a smooth transition while other companies were unable to switch and thus has to halt or shut down. For instance - most industries and business in Switzerland have been working virtually for months and they had a very smooth transition as the virtual working has been encouraged and in practice for over 10 years (Ozguler, 2020). Figure 1 shows the NORM and NEW NORM in the construction industries.

[Figure 1 follows the paragraph] 


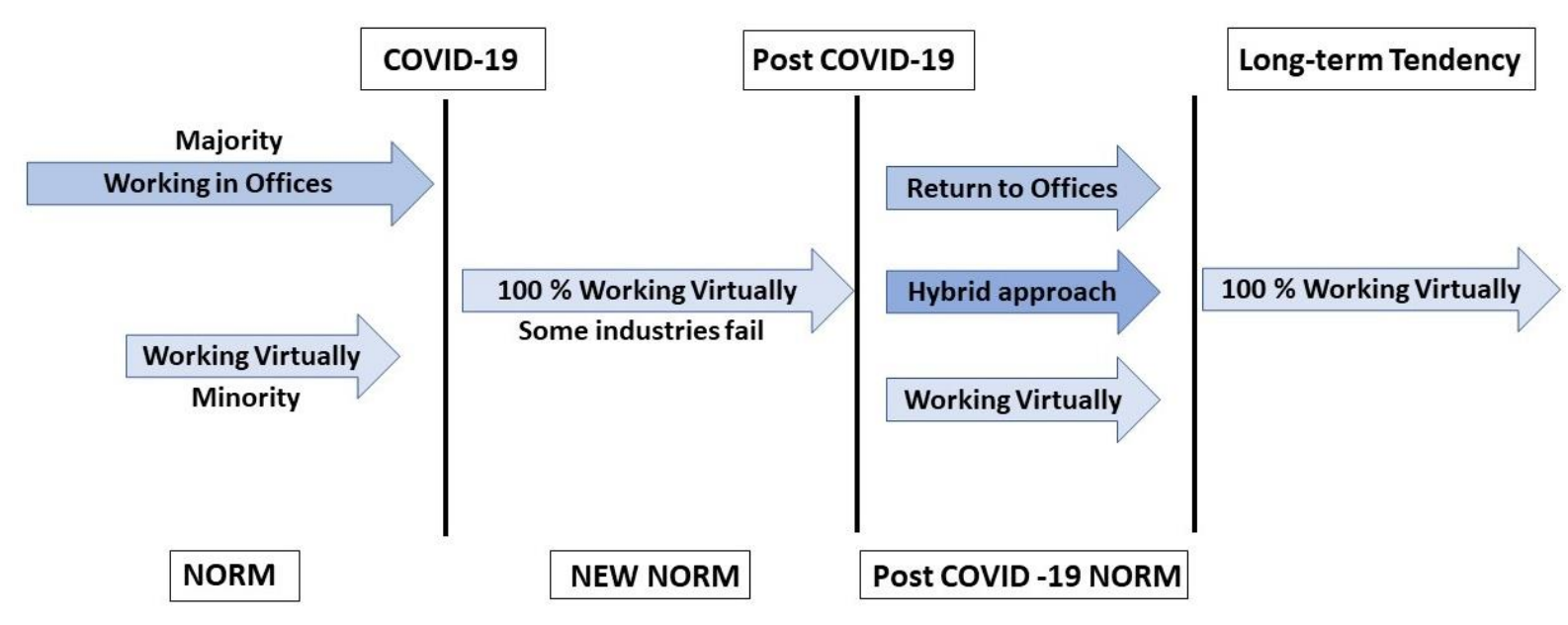

Figure 1: Pre-COVID-19 NORM and NEW NORM under COVID-19 and Post COVID-19 NORM (Source: adopted from Ozguler, 2020)

It is fair to say that COVID-19 will be with us for a longer period, at least next several months. Most of the workers will be reluctant to return to their offices as they will have already adapted to the NEW NORM. Thus, the owners, decision makers and every professional should be able to compare the pros and cons of each approach and need to make appropriate decisions depending on the nature of work. Further, they might have to choose a completely new, i.e., hybrid approach, which will be a blend of physical and virtual. In this hybrid approach, some categories of workers may need to be physically present to work, some may work virtually, and while others may be categorized as hybrid group where the workers may work both at office stations and virtually.

Moreover, in the long run, it is a great challenge for the professional and decision makers to decide as in how the company would run weighing the pros and cons of several approaches physical, virtual and hybrid. Alongside, the working environment and culture of the organization will have already changed, and new and sophisticated technologies are likely to execute most 
physical works thus avoiding the physical presence of workers on jobsites. Thus, returning to offices and teams working physically may not be a viable option any longer as shown in Figure 1.

\section{COVID-19 implications on construction industry}

The impact of COVID-19 has been felt through all segments in the construction industry, both operationally and financially (Cherukur et al., 2020, Deloitte, 2020a). The delays, disruptions, suspension and termination of contracts, limited resources and therefore price escalation of material, equipment and labor, additional cost on maintaining site security and safety, and impacts on workforce availability due to illness and retention of key skilled employees have affected operational process of the industry. Additionally, such operational implications leading to cancellation of contracts has added financial difficulties in construction projects.

\subsection{Managing projects and construction risks during the coronavirus pandemic}

The basics of risk management process: identifying risks, analysis and generation of response strategies based on expected outcomes, and finally carrying out identification, analysis and response generation steps, based on feedback received on actual outcomes, repetitively throughout the project cycle, are fully applicable and actually being applied during the coronavirus pandemic (Adhikari et al., 2020) (Zavadskas et al., 2010) (Cooper et al., 2013). Thus, the project managers and contractors need to adopt their existing Risk Action Plans with necessary updates and revisions as required. The risk management techniques should include all critical members involved in the project at different phases (Ranganath et al., 2020). Further, risk management techniques should provide more accurate and decisive making outcome to help 
management mitigate or reduce the severity of risks through inclusion or exclusion of alternative solutions based on hard cut-offs.

The COVID-19, however, has introduced new challenges such as distancing on job sites, travel restrictions for project engineers, site safety and security, labor shortages, supply chains, unanticipated and prolonged delays, reduced productivity and cost overruns (Naulleau \& Swetchine, 2020). The complete nature and duration of these risks are not fully known, and it is yet not clear how the construction projects will adopt and cope with these new challenges. However, the following best practices and guidelines can help construction industry for proper functioning of construction projects and effective risk management during this period of pandemic.

Pre-construction/Design Development Planning: The pre-construction activities, such as budgeting, cost savings, detailed plans for bidding, design and material issues, have become more important during this phase as this can be largely done remotely regardless of currently enforced restrictions, and this will later help to proceed with the construction phase efficiently as the country re-opens. In lieu of current pandemic, it is advisable to have added considerations such as remote working spaces, individual working space, and touchless faucets, doors, etc. during this phase (gould+ratner, 2020a).

Detailing and Site Safety Plan: Health and safety of the workforce has now been, more than ever, a great concern and a priority in most construction industries. The risk management thus should be compliant with government rules and advisory opinions and must be flexible in adopting future changes in regards to workers safety (gould+ratner, 2020a). Some minor yet essential measures for site safety could be increased monitoring of the site and employees, 
increased sanitation stations, limited travels of employee and record keeping of health and safety related issues.

Site Security: The pandemic could potentially delay the work for months thus the risk management plan should provide site security using one of several approaches such as fencing or barriers, electronic security, guard services.

Supply Chain Disruptions: The supply of materials, especially the imported materials, has been and will be impacted due to the coronavirus pandemic. Thus, a full understanding of existing sources is necessary and potential alternate/new sources should be identified for future procurements in the event of supply shortages. Following the disruptions, whole life costing (Manege \& Kennedy, 2020; Meng and Harshaw, 2013, Opoku, 2013) can be more vital in optimized selection of materials, equipment and other components thus increasing economic sustainability.

Changes to Workforce and Impacts on Scheduling: Alike the material shortages, the workforce availability has been impacted by the coronavirus leading to schedule delays in projects. Thus, the risk management should adopt strategies to keep up with the potentially reduced workforce to mitigate these delays. Some approaches could be the increased sanitation measures in the workplace and safe social distancing at workplace to keep the workers safe, allowing overtime to counteract the delays, relaxing rules on "work hours", and record keeping of the delays and their impacts (gould+ratner, 2020a).

\subsection{Keys to successful project planning and risk management during the coronavirus pandemic}

Construction industry is a highly fragmented industry which now has even been more 
challenging due to the teams distributed and separated physically. Further, the frequently changing governmental regulations, and unprecedented changes in availability of labor and materials has added more challenge in the construction projects. Thus, teamwork and collaboration are required more than ever for effective risk management and proper functioning of construction projects. This section summarizes on some key strategies that will help manage the construction projects and mitigate risks during the difficult situations like coronavirus pandemic.

Use of technology and tools: Coronavirus pandemic will be with us for a long time thus it is evident that new normal is here to stay and this implies that sophisticated technologies such as artificial intelligence (AI)-based technologies will be the future. The NEW NORM has brought many possibilities along with the challenges. The fear of most project managers that the wide use of technology would occupy their positions, has now been superseded and the current pandemic has shown that technology rather can be an augmentation to human (Ozguler, 2020).

AI-based technologies are being used in a variety of construction related works. The AI and machine learnings systems can be used to process meta data to make future predictions thus aiding in bidding of projects. AI-based technologies such as robots are being used to monitor jobsite progress with real time and are used to conduct repetitive works in construction thus improving jobsite productivity (Walch, 2020). Autonomous drones and rovers equipped with high-definition cameras and LIDAR are used in construction sites for transporting materials and in taking photographs and scan of the construction site. The scans are then used in comparing against the Building Information Modelling (BIM models), 3D drawings, construction schedule, and estimates to inspect the quality of the work performed. Further, deep-learning algorithms are used to identify and report errors in work executed. In addition, technologies such as Telematics, 
Internet of Things (IoT), Virtual Reality (VR), Augmented Reality (AR) and 3D printing can be useful in construction during this new normal.

The coronavirus pandemic has provided the construction industries with an opportunity to use the sophisticated technologies in building a culture of actionable knowledge-sharing and knowledge creation that strengthen organizational connectivity and resilience towards disruptions and uncertainties in the new normal (Deloitte, 2020b). And, it is strongly likely for industries to consider making investments on such systems, and for project managers to be more eager to benefit from those (Phillips, 2020). Also, the construction industries need to look at technology as an augmentation or collaboration strategy as opposed to the convention thinking of complete replacement of humans with technology (Deloitte, 2020b).

Effective communication: The coronavirus pandemic has resulted in geographic dispersion of team members, and communication has now become the most important element in project management (Khahro et al., 2020; Thornton, 2020). Communication among team members is done remotely using tools and platforms such as emails, Microsoft projects, google meetings, zooming, skype, facetime, WhatsApp, IMO, and WeChat. In addition, tools such as instant messaging programs, video conferencing platforms, project management software, and cloud-based document storage/file sharing suites are used for accessing the information and materials from any location.

Data centralization and effective monitoring: In the current environment of lockout, organizations have no choice but to centralize information including schedules, correspondence, worksheets, pieces of documentation, reports, and records. Without a centralized information system, a good project management activity will no longer exist. The solution is to implement a large-scale project \& portfolio management tool, and any other small-scale system. 
Just like with data centralization, the context forces us to monitor project status more closely. Monitoring is more than ever necessary for effective project management. An effective reporting can be accomplished with a good data centralization method, and the project can be controlled properly. Monitoring and centralization processes should be coordinated so that information in real time can take immediate action if necessary. Pre-defined milestone and key performance indicator will be helpful in this case. Using information technology real-time monitoring dashboards can be created and visualization of project progress in real-time will be more effective like various tools of BIM and Digital Twin. A recent article by Zhang et al. (2020) evaluates the technical feasibility of applying ultra-wide band technology in construction progress monitoring which has shown promising results. Warning systems can also be integrated into these systems for potential issues or risks.

Adoptability of new work culture: As the pandemic spread through, the workers showed the resilience and adaptability with quick transition and contribution under their new roles (Deloitte, 2020b), and the industries should now be focusing on ways to encourage and create opportunities for workers to continue to grow and adapt based on their potential. Proper communication and collaboration, acceptance of digital culture in the workplace, building trust and resilience among teams and special attention to the workers' treatment and security are some of the key areas to be prioritized that can ensure better adaptability to the new norm during this pandemic. In addition, humility, empathy, regular contacts, and openness among team members by internal emails, social media channels, applications such as Microsoft Teams and forums can further aid in smooth transition and adoptability of new work culture.

Team members safety: Safety of every team member at the project is very critical, especially in current COVID-19 pandemic. Therefore, the safety plans should be revised, and 
new safety guidelines will be designed based on the guidelines given by the government and concerned authorities. It was challenging to create the culture of wearing Personnel Protective Equipment's (PPE's); now cultivating the new trend of extra PPE due to COVID-19 will be more challenging. Virtual Reality (VR) may have a significant effect on the construction industry in two fields such as safety awareness and training of equipment operators. VR can be used in areas with enclosed spaces or work at height or regulated environment and can also be used to train staff on anything from running crane and excavators to welding and masonry jobs.

Augmented Reality (AR) is another technology that could dramatically enhance construction site safety. AR can be deployed on the jobsite in many ways, either to create a more comprehensive safety plan or to provide instruction on heavy machinery using actual equipment on specific sites with increased risks (Jones, 2020). Some common and essential safety practices for the control of spread of COVID-19 in construction sites are physical distancing, continuous monitoring, modifications and adjustments of work schedules, site logistics and control, worker education, and administrative action and policies (Hollingsworth, 2020).

\subsection{Creating a response to the coronavirus pandemic}

The coronavirus pandemic along with the constantly changing guidelines, orders and selfimposed restrictions on construction projects have brought unprecedented changes and adverse impacts on the projects. The industries, thus, need to develop response plans and should be looking long-term to combat the impacts of COVID-19. It is more than ever a need for all industries and decision makers to evaluate and assess all available options in making right decisions for smooth running of construction projects and managing of construction risk. Table 1 summarizes the experts' opinion on key areas where construction needs to focus and highlights 
some strategic guidelines for creating a response.

[Table 1 follows the paragraph]

Table 1: Creating a response to the coronavirus pandemic

\begin{tabular}{|l|l|l|}
\hline Actions/Sector & Description & Ref. \\
\hline Review of projects & $\begin{array}{l}\text { Assess the project stage and ongoing activities and } \\
\text { develop proactive measures for a shift in onsite work. } \\
\text { Identify services that can be operated offsite to limit }\end{array}$ & (Deloitte, 2020c) \\
\hline
\end{tabular}




\begin{tabular}{|c|c|c|}
\hline & $\begin{array}{l}\text { schedule delays. } \\
\text { Develop a mitigation plan for potential slowdowns, } \\
\text { shutdowns, and project restarts. } \\
\text { Focus design and shoring up contracts to limit risks } \\
\text { associated with uncertain schedules. } \\
\text { Develop project start-up plan. }\end{array}$ & \\
\hline $\begin{array}{l}\text { Schedule assessment/ } \\
\text { time-impact analysis }\end{array}$ & $\begin{array}{l}\text { Document current schedule status. } \\
\text { Identify latent delays in the schedule, determine causation } \\
\text { and attribute delay as appropriate. }\end{array}$ & \\
\hline Resource planning & $\begin{array}{l}\text { Revisit resource plans and identify current key resources } \\
\text { as well as those required for the duration of the project. }\end{array}$ & \\
\hline Job site rules & $\begin{array}{l}\text { Revisit job sites and ensure strict implementation of } \\
\text { changes in response to COVID-19 guidance. } \\
\text { Evaluate the new liabilities at job site and assess cost } \\
\text { impacts of additional safety protocols such as enhanced } \\
\text { cleaning, reduced workforce, and other modifications. }\end{array}$ & \\
\hline Risk analysis & $\begin{array}{l}\text { Identify the new risks and their impacts on cost and } \\
\text { schedule performance of the project. } \\
\text { Prioritize the risk management plans based on severity } \\
\text { and probability of occurrence of risks. } \\
\text { Assess the costs and benefits of project shutdowns versus } \\
\text { slowdowns. }\end{array}$ & \\
\hline $\begin{array}{l}\text { Contract review and } \\
\text { dispute mitigation }\end{array}$ & $\begin{array}{l}\text { Review the contracts to understand force majeure clauses } \\
\text { and whether pandemics are defined as force majeure } \\
\text { events. }\end{array}$ & $\begin{array}{l}\text { (Cowart, 2020, } \\
\text { Deloitte, 2020c) }\end{array}$ \\
\hline $\begin{array}{l}\text { Review insurance } \\
\text { coverage }\end{array}$ & $\begin{array}{l}\text { Check if the insurance policies cover the losses in projects } \\
\text { Keep a detailed record of events and their impacts on } \\
\text { projects to help support claims. }\end{array}$ & \\
\hline $\begin{array}{l}\text { Clear \& Compliant } \\
\text { notice }\end{array}$ & $\begin{array}{l}\text { Identify express notice provisions for claiming delays and } \\
\text { additional costs, including the time period in which } \\
\text { proper notice must be provided, to whom notice must be } \\
\text { provided, and method of delivery. }\end{array}$ & (Cowart, 2020) \\
\hline
\end{tabular}




\begin{tabular}{|c|c|c|}
\hline $\begin{array}{l}\text { Suspension \& } \\
\text { Termination Clauses }\end{array}$ & $\begin{array}{l}\text { Evaluate and understand the contractual provisions that } \\
\text { will give right to terminate an agreement and receive pre- } \\
\text { determined compensation if suspension persists beyond a } \\
\text { stated amount of time. }\end{array}$ & \\
\hline $\begin{array}{l}\text { Document Delays } \\
\text { and Disruptions }\end{array}$ & $\begin{array}{l}\text { Keep record of any effects COVID-19 has on a project. } \\
\text { Be specific in record-keeping, documentation, and updates } \\
\text { to schedules, time sheets, and costs, identifying which are } \\
\text { related to COVID-19 and why. }\end{array}$ & \\
\hline $\begin{array}{l}\text { Identify Potential } \\
\text { Challenges Early }\end{array}$ & $\begin{array}{l}\text { Take proactive approach in mitigating delay or disruption } \\
\text { and maintaining clear record of those efforts. } \\
\text { Establish lines of communication with vendors and } \\
\text { subcontractors to assess labor and supply issues, } \\
\text { contingency plans and protocols, and alternatives. }\end{array}$ & \\
\hline $\begin{array}{l}\text { Engage with } \\
\text { stakeholders }\end{array}$ & $\begin{array}{l}\text { Understand the effect of COVID-19 on employees and } \\
\text { partners of the supporting organization and provide direct } \\
\text { support to groups that are most impacted. }\end{array}$ & \multirow[t]{5}{*}{ (Deloitte, 2020d) } \\
\hline Promote virtual work & $\begin{array}{l}\text { Expand virtual work capabilities using available tools and } \\
\text { best practices that support collaboration, productivity, } \\
\text { and culture continuity. } \\
\text { Use data to measure the success of your efforts and } \\
\text { expand practices that increase performance. }\end{array}$ & \\
\hline Own the narrative & $\begin{array}{l}\text { Develop strong and consistent communication channels to } \\
\text { employees and partners. } \\
\text { Keep all stakeholders abreast of relevant health updates, } \\
\text { local impacts, training, and desired cultural behaviors. }\end{array}$ & \\
\hline $\begin{array}{l}\text { Increase support for } \\
\text { help desks }\end{array}$ & $\begin{array}{l}\text { Enhance virtual work support to enable new ways of } \\
\text { working and support a comprehensive employee and } \\
\text { partner experience. }\end{array}$ & \\
\hline $\begin{array}{l}\text { Organizational } \\
\text { preparedness }\end{array}$ & $\begin{array}{l}\text { Coordinate efforts across the organization. } \\
\text { Monitor relevant health/travel advisories by geography. } \\
\text { Assess market and financial impacts and risks. } \\
\text { Build a transformation roadmap. }\end{array}$ & \\
\hline
\end{tabular}




\begin{tabular}{|c|c|c|}
\hline Work & $\begin{array}{l}\text { Establish a business response and continuity office. } \\
\text { Confirm critical roles and backup plans. } \\
\text { Evaluate the actual work of your company and how it } \\
\text { might be changed. } \\
\text { Understand what work is mission-critical and what can be } \\
\text { deferred or deprioritized. }\end{array}$ & (Deloitte, 2020e) \\
\hline Workforce & $\begin{array}{l}\text { Show up for your people-set the tone at the top. } \\
\text { Develop a plan for your whole workforce. } \\
\text { Define your communication strategy and make it visible. } \\
\text { Educate employees about COVID-19 symptoms and } \\
\text { prevention. } \\
\text { Establish employee support procedures. } \\
\text { Create strategies for a temporary labor reduction. } \\
\text { Prepare plans for site disruption and re-activation. } \\
\text { Develop clear protocols and obligations for employees } \\
\text { who are at risk. } \\
\text { Review leave policies. } \\
\text { Prepare for increased absenteeism and work refusal. } \\
\text { Review anti-discrimination policy and practices. }\end{array}$ & \\
\hline Workplace & $\begin{array}{l}\text { Prepare your worksite for containment and } \\
\text { contamination. } \\
\text { Update travel and meeting protocols. } \\
\text { Review your social media policy and guidelines. } \\
\text { Consider the sources of 'news' and information in the } \\
\text { workplace. }\end{array}$ & \\
\hline
\end{tabular}

\subsection{Safety measures to prevent the spread of coronavirus}

Occupational Safety and Health Administration (OSHA) (OSHA, 2020) and the Centers for Disease Control and Prevention (CDC) (CDC, 2020) have issued guidance for employers in preparing for and responding to COVID-19 risks. Some of the key points include the following: 
(1) Develop an infectious disease preparedness and response plan.

(2) Consider how workers could be exposed to COVID-19, as well as the worker's risk factors and controls necessary to address risks.

(3) Prepare for the possibility of absenteeism, changes in patterns of commerce and interruptions in supply and delivery.

(4) Encourage workers to stay home when they are sick. Isolate and send home workers who come to work sick.

(5) Establish policies that promote social distancing.

(6) Promote frequent hand washing (with soap and water for 20 seconds) or use of alcoholbased hand sanitizer. Also remind workers to cover their mouths when coughing or sneezing.

(7) Discourage workers from sharing phones and other tools and equipment when possible.

(8) Regularly disinfect work areas and equipment.

\section{Post COVID-19 implications on construction industry}

The post-pandemic era of construction is expected to be different than how the industry today is as they will highly depend upon technology and virtual teams. Prior to COVID-19, the team worked together in proximity with each other and under the direct supervision of project managers and leaders. While in the virtual environment, most works will be done in the proximity of family members, thus, it will be more challenging for leaders to recover a poorly run projects, and only exceptional leaders will be able to have the same impact as in the physical working environments. But, on the other side, the failures will be more acceptable in the virtual working environments as the financial losses due to project failures will possibly be low as there 
will be no indirect costs (such as building, heating, admin staff) allocated in the project.

\subsection{Cost}

The next few months will be turbulent, fueled by uncertainty at all levels of construction industry. The rapidly changing information related to COVID -19 had led to inconsistency related to cost with some projects experiencing cost increases while others remain somewhat steady. Some factors that could increase the costs could be the hindered labor productivity by COVID -19 protocols, extended schedules and increased project requirements such as additional cleaning of common areas, job trailers, more frequent emptying of trash receptables, hand wash stations with warm water, additional PPE, logistics for remote collaboration and job office/size configuration to facilitate social distancing (Lachapelle, 2020). On the other side, bidding aggression due to fewer available opportunities and increased competition may counterbalance to the forces of increasing costs (Lachapelle, 2020). The net effect however is unclear and will depend heavily on the duration businesses and jobs are closed and the speed of subsequent economic recovery (Lachapelle, 2020) (Bray, 2020).

\subsection{Materials/ Supply chain}

The construction industries largely depend on the continuous availability and supply of materials. The supply chain post COVID-19 will be disrupted at both regional and global levels. The severity of pandemic varies with the type and size of the industry. Small or medium sized industries that relies on local supply, few suppliers, and which are not able to switch sourcing may find more difficulty in thriving the post-COVID-19 impacts as compared to large industries with global supply networks. Further, there will be lot more uncertainty in the post-COVID-19 
market of materials supply. There are chances that the price for construction materials will fall due to economic recession. On the other side, it is likely that the cost might increase as the factories remain shut down with workers quarantine for a prolonged period (PNC Insights, 2020).

\subsection{Labor/ Workforce}

As a result of huge layovers and economic recession due to COVID-19 pandemic, there will be the shortage of workers in the construction industry. The industries must rely more on local workforce thus the cost for labor is expected to rise. Also, there will be the major concern of workers safety and health. Thus, the construction industries will start relying more on technologies and less on human workforce. Some construction technologies that has evolved and are expected to be the driving workforce in construction industries are drones, robots and autonomous heavy equipment's (Jones, 2020). For instance - drones will be used in construction jobsites to determine the potential hazards and to monitor workers and their safety, robots will be heavily used to perform repetitive tasks, autonomous heavy equipment's will be used in performing extensive labor works such as excavation and grading. Use of these technologies will help industries alleviate the risk of labor shortages, augment workers performance and thus the overall productivity.

\subsection{Safety and training}

Workers safety has always been a major issue in the construction industry, and this will be the number one priority with far-reaching implications for construction as we enter the post COVID19 environment. Thus, the industries will be strict in enforcing safety measures such as 
wearables and new technologies such as augmented reality and virtual reality, and site sensors will be incorporated in the construction jobsites (Jones, 2020).

Post COVID-19, the safety of workers can be improved by incorporating wearable tech in existing safety apparel and PPE's such as gloves, safety vests, work boots, hard hats. These can be made more sophisticated and safer by embedding biometrics and environmental sensors, GPS trackers and other sensors to monitor workers, which will help in reducing jobsites accidents and casualties. In addition, to comply with OSHA regulations, smart clothing with features to monitor vital signs like temperature, heart rate and respiration rate of workers, site sensors in workplace to monitor workers movement and potential hazards will help ensure a safe working environment. Further, use of VR and AR in construction can play a significant role in training of workers and improving safety of construction sites.

Lastly, it may prove cost-effective for construction industries and job sites to adopt new deigns and modifications in jobsites and buildings such as clean air supply, exhaust ways for contaminated air, continuous supply of fresh air from outdoors and mechanisms for cleaning air within the room (Ingram, 2020).

\section{Future of construction: a transformation of work, workforce, and workplace}

Construction has always been a dynamic industry (Ribeirinho et al., 2020), and more of unprecedented changes and rate of disruption are expected in the next normal of construction. The changes in market characteristics such as labor and material supply, need for increased site safety, stricter regulations on work-site sustainability, evolving needs of customers will be driving the construction industries in Post COVID-19 NORM. Significant transformations of work, workforce and workplace are expected in the new normal and experts in the field have 
shared their opinions in thriving and building a resilient future amidst COVID-19 pandemic (Deloitte, 2020d, 2020e, 2020f).

Most or all the works will be digitized through advances in technologies such as use of AI, robotics, IoT, cloud and other technologies and the conventional idea of working from a specific physical location will be challenged. And the future workforce will comprise of humans and technology working in concert with each other or independently at their best. Humans will drive the innovation and creativity while technologies will be used as augmentation tool in improving the efficiency and productivity of work. Likewise, the workplace will no longer be the same as before. The future workplace will consist of some members working at physical location and some members in virtual environments, and technology and collaboration tools/platforms will be used to support the dynamic work locations (Deloitte, 2020d).

\subsection{Recovery and resilience}

The construction industry has already found ways to respond to the pandemic through the use of technology, patience, flexibility, resilience and adaptability of the workforce. The next step construction industry should focus on is in the recovery and building resilient future amidst coronavirus pandemic where resilience is "the ability to move beyond simply responding and recovering from unexpected challenges and instead findings ways to grow and evolve so that we can create even more value in the future (Deloitte, 2020f)". The reflection and learnings from the current situation should be used to deal with future disruptions (Deloitte, 2020f). Table 2 summarizes the guidelines for developing a recovery and resilience plan as suggested by industry experts. [TABLE 2 follows the paragraph]

Table 2: Developing a recovery and resilience plan to the coronavirus pandemic 


\begin{tabular}{|c|c|}
\hline Action/Guidelines & Ref. \\
\hline $\begin{array}{l}\text { Use the tools and practices for performing works in virtual platforms. } \\
\text { Develop long-term digital vision for the company while continuously } \\
\text { improving and fine-tuning the digital capabilities. } \\
\text { Explore people experience and develop an amazing workplace. } \\
\text { Prioritize new investments in technology, practices, people, and places. }\end{array}$ & (Deloitte, 2020d) \\
\hline $\begin{array}{l}\text { Monitor, assess and re-evaluate market conditions and develop a resilient } \\
\text { supply chain strategy to mitigate risks, improve agility, and ensure supply } \\
\text { security. } \\
\text { Plan for the possible disruptions by identifying alternative sources/suppliers } \\
\text { (Tier } 1 \text { suppliers) and develop contingency plans to secure capacity and } \\
\text { inventory. } \\
\text { Develop effective communication strategies and ensure good relation among } \\
\text { stakeholders. } \\
\text { Safeguard people first. }\end{array}$ & (Deloitte, 2020g) \\
\hline $\begin{array}{l}\text { Accelerate rollout and adoption of digitization. } \\
\text { Invest in the culture and skills needed to operate in the next normal. } \\
\text { Build a control tower across the portfolio. } \\
\text { Bolster supply-chain resilience. } \\
\text { Redeploy capital and resources. } \\
\text { Identify opportunities to shift work off-site. } \\
\text { Get closure to customers and clients. }\end{array}$ & (Biörck et al., 2020) \\
\hline $\begin{array}{l}\text { Create a resilient IT architecture and cybersecurity. } \\
\text {-Ensure confidentiality, integrity, and availability }\end{array}$ & (Deloitte, 2020h) \\
\hline
\end{tabular}

\section{Summary}

The COVID-19 pandemic has generated unprecedented delays, disruptions, and uncertainty on construction projects and has forced the construction industries in adopting more sophisticated 
technologies with increased remote work activities. AI-based technologies, drones, robots, autonomous heavy equipment, connected equipment and tools, augmented reality (AR), virtual reality (VR), and 3-D printed buildings have now been employed as augmentation tool to humans. And the collaboration tools and platforms such as telematics, mobile apps, zooming, skype meetings has been the new mode of communication in construction industries.

Additionally, construction industry post COVID-19 pandemic is expected to be a lot different in terms of using technology as most future works will largely rely on modern technologies.

The construction industries will embrace the technology as the augmentation and collaboration strategy. Increased digitization and rebalanced supply chains geared towards resilience, such as global supply networks, inventories, source switching capabilities, will be observed in the construction industries in next few years of post-pandemic period. And, in long run, increased investments are expected in technology, digitization, off-site construction, building modeling systems and sustainable building materials.

\section{Acknowledgments}

The authors would like to thank the Department of Civil, Environmental and Construction Engineering at Texas Tech University. And, sincere thanks to Dr. Shankar, Professor and Department Chair in the 
Department of Civil, Environmental, and Construction Engineering at Texas Tech University, for his continuous support and guidance in preparing this manuscript.

Author Agreement/Declaration

All authors have seen and approved the final version of the manuscript being submitted. They warrant that the article is the authors' original work, has not received prior publication, and is not under consideration for publication elsewhere.

Declaration of Interest

There are no conflicts. There is no financial/personal interest or belief that could affect the research's objectivity.

Funding Source Declaration

This study did not receive any funding or research grants.

Permission Note

The manuscript does not have any content that needs permission from the published property. Proper acknowledgement and citation have been done when using any prior published material.

Data Availability Statement

No data has been used in the manuscript.

Disclosure Statement

No potential conflict of interest was reported by the authors.

\section{References}

CDC. (2020). Interim Guidance for Businesses and Employers Responding to Coronavirus

Disease 2019 (COVID-19). Centers for Disease Control and Prevention. Retrieved 07 
2020, from https://www.cdc.gov/coronavirus/2019-ncov/community/guidance-businessresponse.html

Cheng Zhang, Weijie Shen \& Zehao Ye. (2020). Technical feasibility analysis on applying ultra-wide band technology in construction progress monitoring. International Journal of Construction Management.

Cherukur, M. R., Reshma, M. S., \& Devi, M. V. (2020). Construction Industry Before And After Covid 19. . Solid State Technology, , 3056-3062.

Cooper, D. F., Grey, S., Raymond, G., \& Walker, P. . (2013). Managing risk in large projects and complex procurements. . In Project risk management guidelines:. Wiley.

Deloitte. (2020a). How the Construction Industry can. Retrieved 7 2020, from https://www2.deloitte.com/ie/en/pages/covid-19/articles/Construction-industry-canmitigate-Covid-19-restrictions.html

Deloitte. (2020b). Returning to work in the future of work Embracing purpose, potential, perspective, and possibility during COVID-19. De. Retrieved from https://www2.deloitte.com/content/dam/Deloitte/lu/Documents/human-capital/lureturning-to-work-future-work-covid-19.pdf

Deloitte. (2020c). COVID-19 Impacts - A proactive response to a shifting planning, design, and construction landscape. Retrieved 7 11, 2020, from https://www2.deloitte.com/content/dam/Deloitte/us/Documents/finance/us-covid-19impact-construction-landscape.pdf

Deloitte. (2020d). Future of Work: Ways of working in uncertain times. Retrieved 7 2020, from https://www2.deloitte.com/us/en/pages/about-deloitte/articles/ways-of-working-tosustain-and-thrive-in-uncertain- 
times.html?id=us:2ps:3gl:consem21:eng:cons:060920:nonem:na:i2i0iCxo:1191982799:4 40661617432:b:Future_of_Work:Ways_of_Working_BMM:nb

Deloitte. (2020e). COVID-19: Practical workforce strategies that put your people first.

Retrieved 7 11, 2020, from https://www2.deloitte.com/global/en/pages/aboutdeloitte/articles/practical-workforce-strategies-that-put-your-people-first.html

Deloitte. (2020f). New architectures of resilience. Retrieved 7 11, 2020, from https://www2.deloitte.com/content/dam/insights/us/articles/6800_thriving-postcovid/DI_New-architectures-of-resilience.pdf

Deloitte. (2020g). COVID-19's impact on industrial products \& construction firms. Retrieved 7 11, 2020, from https://www2.deloitte.com/global/en/pages/about-deloitte/articles/covid19/covid-19-s-impact-on-industrial-products---construction-firms.html

Deloitte. (2020h). COVID-19: Work from anywhere. Cyber everywhere. Retrieved 7 11, 2020, from https://www2.deloitte.com/global/en/pages/about-deloitte/articles/covid-19/covid19-work-from-anywhere-cyber-everywhere.html

Gallagher. (2020). Construction Guidance for Coronavirus (COVID-19) Pandemic. Retrieved 07 02, 2020, from https://www.ajg.com/us/news-and-insights/2020/mar/constructionguidance-for-coronavirus-covid-19-pandemic/

Gamil, Y., \& Alhagar, A. (2020). The Impact of Pandemic Crisis on the Survival of Construction Industry: A Case of COVID-19. . Mediterranean Journal of Social Sciences, , 11(4), 122122.

Gérard Naulleau, Nicolas Swetchine. (2020). Managing “Large Projects” through the Covid-19 crisis. ESCP Research Institute of Management (ERIM). Retrieved 07 02, 2020, from https://academ.escpeurope.eu/pub/IP\%202020-34-EN.pdf 
gould+ratner. (2020a, 03 20). Retrieved 07 02, 2020, from Identifying and Managing Construction Risks During the Coronavirus Pandemic: http://www.gouldratner.com/publication/identifying-and-managing-construction-risksduring-the-coronavirus-pandemic

Grant Thornton. (2020, 03 25). virtual-project-management-through-covid-19. Retrieved 2020, from Virtual Project Management through COVID-19: https://www.grantthornton.ie/insights/blogs/virtual-project-management-through-covid$19 /$

Hendershot Cowart. (2020, 3 19). CORONAVIRUS CONSTRUCTION DELAYS \& DISRUPTIONS: MANAGING RISKS. Retrieved 7 2, 2020, from https://www.hchlawyers.com/blog/2020/march/coronavirus-construction-delaysdisruptions-mana/

Hollingsworth, J. . (2020). Construction safety practices for covid-19. . Professional Safety, , 65(6), 32-34.

Ipek Sahra Ozguler. (2020). Insights Report: Project Management After Covid-19. PM World Journal, IX(V). Retrieved 07 02, 2020, from https://pmworldlibrary.net/article/projectmanagement-after-covid-19-insights-from-11-project-management-leaders-from-aroundthe-world-insights-report/

Jared Lachapelle. (2020, 3 14). COVID-19: Cost Implications. Retrieved 7 2, 2020, from https://www.consigli.com/covid-19-impact-material-supply-update/

Jonas Biörck, Jose Luis Blanco, Jan Mischke, Maria João Ribeirinho, David Rockhill, Erik Sjödin, and Gernot Strube. (2020). How construction can emerge stronger after coronavirus. Retrieved 7 12, 2020, from McKinsey \& Company : 
https://www.mckinsey.com/industries/capital-projects-and-infrastructure/ourinsights/how-construction-can-emerge-stronger-after-coronavirus

Julian Bailey, Nicolas Bouchardie, Ignacio Madalena. (2020, 4 14). COVID-19: The Current Impact on Construction and Engineering Projects. Retrieved 07 2020, from https://www.whitecase.com/publications/alert/covid-19-current-impact-constructionengineering-projects

Kathleen Walch. (2020). AI Transforming The Construction Industry. Retrieved 7 12, 2020, from Forbes: https://www.forbes.com/sites/cognitiveworld/2020/06/06/ai-transforming-theconstruction-industry/\#74f817be74f1

Kendall Jones. (2020). Construction Technology is Reshaping the Industry. Retrieved 7 10, 2020, from constructconnect : https://www.constructconnect.com/blog/technologyreshaping-construction-industry

Kenny Ingram. (2020). FROM COVID-19 TO OTHER DISASTERS: HERE'S HOW CONTRACTORS CAN HELP PROJECT OWNERS MITIGATE RISK. Retrieved from https://www.enr.com/articles/49303-from-covid-19-to-other-disasters-heres-howcontractors-can-help-project-owners-mitigate-risk

Khahro, S. H., Ali, T. H., Vighio, A. A., Khahro, Q. H., \& Moriyani, M. A. . (2020). Post Pandemic Project Management Key Skills and Challenges. . Journal of Talent Development and Excellence, , 12(3s), 2253-2260.

Kushal Adhikari, Lochana Poudyal, Venky Shankar. (2020, 08). Managing risk and uncertainty in construction projects: A holistic review Managing risk and uncertainty in construction projects: A holistic review. Preprint. ResearchGate. Retrieved from https://www.researchgate.net/publication/343876814_Managing_risk_and_uncertainty_in 
_construction_projects_A_holistic_review_Managing_risk_and_uncertainty_in_construct ion_projects_A_holistic_review?fbclid=IwAR2Wk9zDYUkKg2MEgATeYuqtnbG0fRw HuAVXTovTI3128hnH_

Laing, T. . (2020). The economic impact of the Coronavirus 2019 (Covid-2019): Implications for the mining industry. . The Extractive Industries and Society.

Maria João Ribeirinho, Jan Mischke, Gernot Strube, Erik Sjödin, Jose Luis Blanco, Rob Palter, Jonas Biörck, David Rockhill, and Timmy Andersson. (2020). The next normal in construction: How disruption is reshaping the world's largest ecosystem. Retrieved 712 , 2020, from McKinsey \& Company : https://www.mckinsey.com/industries/capitalprojects-and-infrastructure/our-insights/the-next-normal-in-construction-how-disruptionis-reshaping-the-worlds-largest-ecosystem

MARLON BRAY. (2020, 3 30). Opinion |COVID-19 impact on construction costs and escalation. Retrieved 7 2, 2020, from https://www.altusgroup.com/services/insights/covid-19-impact-on-construction-costsand-escalation-in-the-short-medium-and-long-term/

Meng X, Harshaw F. (2013). The application of whole life costing in PFI/PPP projects. In S. a.D. Smith (Ed.), 29th Annual ARCOM Conference, (pp. 769-778). Association of Researchers in Construction Management.

N. Ranganath , Debasis Sarkar, Preet Patel \& Smit Patel. (2020). Application of fuzzy TOPSIS method for risk evaluation in development and implementation of solar park in India. International Journal of Construction Management. 
Nicola, M., Alsafi, Z., Sohrabi, C., Kerwan, A., Al-Jabir, A., Iosifidis, C., ... \& Agha, R. . (2020). The socio-economic implications of the coronavirus pandemic (COVID-19): A review. International journal of surgery (London, England), , 78, 185.

Opoku A. (2013). The application of whole life costing in the UK construction industry: benefits and barriers. IJAEC, 2(1):35-42.

OSHA. (2020). Guidance on Preparing. U.S. Department of Labor, Occupational Safety and Health Administration. Retrieved 2020, from https://www.osha.gov/Publications/OSHA3990.pdf

Phillips, Zachary. (2020). COVID-19 will spur construction's tech use. Retrieved 7 12, 2020, from McKinsey: https://www.constructiondive.com/news/mckinsey-covid-19-will-spurconstructions-tech-use/578335/

PNC Insights. (2020). COVID-19 Scrambles Projections for Materials Prices. Retrieved 72 , 2020, from https://www.pnc.com/insights/corporate-institutional/gain-marketinsight/covid-19-scrambles-projections-for-materials-prices.html

Robert C. Epstein, Zackary D. Knaub, Steven C. Russo, David C. Jensen, John L. Mascialino. (2020, 04 15). For Developers and Owners: How COVID-19 Is Affecting Construction Projects and Actions You Should Consider. Retrieved 2020, from https://www.natlawreview.com/article/developers-and-owners-how-covid-19-affectingconstruction-projects-and-actions-you

S. L. Manege \& C. J. Kennedy. (2020). Investigating whole life costing awareness in Tanzania building construction industry. International Journal of Construction Management.

WHO. (2020). Coronavirus disease (COVID-19) pandemic. (World) Retrieved 10 31, 2020, from https://www.who.int/emergencies/diseases/novel-coronavirus-2019 
Zavadskas, E. K., Turskis, Z., \& Tamošaitiene, J. (2010). Risk assessment of construction projects. Journal of civil engineering and management, , 16(1), 33-46. 